\title{
Mixed Acute Allergic Angioedema and Urticaria Associated with Olanzapine Treatment - A Rare Case Report
}

\section{Obayi $0^{1 *}$ and Okoh $\mathrm{N}^{2}$}

${ }^{1}$ Dept of Psychiatry, Ebonyi State University \& Federal Teaching Hospital, Nigeria

${ }^{2}$ Dermatology Unit, Dept of Internal Medicine, Ebonyi State University \& Federal Teaching Hospital, Nigeria

*Corresponding author: Dr. N Okwudili K Obayi, Dept of Psychiatry, Ebonyi State University, Abakaliki or Dept of Psychiatry, Federal Teaching Hospital, Abakaliki, Nigeria, Tel: +2348037784345; Email: nokobayi@gmail.com

\section{Abstract}

Adverse cutaneous reactions are common, being associated with many prescribed drugs including psychotropic medications. Very few cutaneous reactions with olanzapine have been described in the literature but none of these reports came from Nigeria, a country where clinicians have joined the developed world in prescribing increasingly atypical antipsychotics such as olanzapine.

We report a case of a 30-year old clergy with paranoid schizophrenia who developed acute angioedema with urticaria shortly after she was commenced on olanzapine. The lesion resolved on withdrawal of olanzapine but re-occurred following a re-challenge.

Drug-related skin reactions are probably under-reported, may be because most are mild and self-limiting. Clinicians should know and educate their patients on antipsychotic-related skin lesions. Awareness of this rare side effect will lead to timely reporting, prompt management, and eventual better compliance with psychotropic medications.

Keywords: Olanzapine; Angioedema; Urticaria

Abbreviations: D2: Dopamine type 2; ACRs: Adverse Cutaneous Reactions; TEN: Toxic Epidermal Necrolysis; DRESS: Drug Rash with Eosinophilia and Systemic Symptoms.

\section{Introduction}

Olanzapine, an atypical antipsychotic drug useful for conditions such as schizophrenia, mania, and other psychotic syndromes has its antipsychotic activity mediated through a combination of serotonin type 2 (5-
$\left.\mathrm{HT}_{2 \mathrm{~A}}\right)$ and dopamine type $2\left(\mathrm{D}_{2}\right)$ antagonism, and also via other multiple neurotransmitter receptors: $\mathrm{D}_{1}, \mathrm{D}_{4}, \alpha_{1}, 5$ $\mathrm{HT}_{1 \mathrm{~A}}$, muscarinic $\mathrm{M}_{1}-\mathrm{M}_{5}$, and $\mathrm{H}_{1}$ receptors [1].

Adverse cutaneous reactions (ACRs) are common, potentially life-threatening or symptomatically and cosmetically unappealing side effects of many prescribed drugs. Psychotropic medications can cause cutaneous rashes and eruptions, which may present in various forms and severity; often mild and may sometimes go unnoticed or without much concern by the patient but could be severe at times, leading to life-threatening complications. 
Dermatological side effects of psychotropic medications have been mostly reported with the group of mood stabilizers and antiepileptic agents, particularly for the carbamazepine and lamotrigine and can even manifest as the Stevens Johnson syndrome or Toxic Epidermal Necrolysis (TEN)/Lyell's syndrome with about 30\% lethality [2].

Some cases of antipsychotic-related skin lesions have been reported. Clozapine, for instance, has been reported to cause angioneuroticoedema [3] and pityriasisrosea-like eruption [4]; risperidone use has been linked to the development of a symmetrical intertriginous and flexural exanthema, also known as Baboon syndrome [5]; and promazine, an aliphatic phenothiazine, has also been reported to cause exanthema medicamentosum [2].

To date, very few cutaneous reactions with Olanzapine have been described in the literature: xanthomatose or lichenoid eruptions [6]; drug rash with eosinophilia and systemic symptoms (DRESS) syndrome [7]; vasculitis [8,9]; acute generalized exanthematous pustulosis [10]; hyperpigmentation [11]; skin rash with the long-acting pamoate form [12]; pellagroid skin lesion [13]; and Stevens-Johnson syndrome [14]. None of these reports, however, came from Nigeria, a country where clinicians have joined the developed world in prescribing increasingly atypical antipsychotics like olanzapine.

We report a case of olanzapine-induced skin lesion, the first to be noticed in our treatment facility our daily prescription of olanzapine for many years notwithstanding.

\section{Case Report}

A 30-year old clergy with the first episode of mental illness, characterized mainly by hearing of voices of unseen church members running commentary over every of her activities, firm belief that people knew her unspoken thoughts, and false accusation of male pastors in the church of ganging up against her.

A diagnosis of paranoid schizophrenia was made. She was placed on haloperidol, 5mg twice daily and subsequently switched over to olanzapine $110 \mathrm{mg}$ at night), after two weeks as she became increasingly rigid and tremulous despite an added benzhexol. However, she developed bilateral leg swelling and skin rashes few days after she commenced olanzapine. The rashes were nonitching, slightly painful, and only in the lower limbs and mouth. The skin lesion was not associated with any fever, chills, headache, vomiting, cough, arthralgias or myalgias.
She reported to the hospital the following day that she noticed the lesion on the mouth and lower limbs (Figures $1 \mathrm{~A} \& 1 \mathrm{~B})$. She objected to a picture of her face or mouth being taken. Olanzapine was stopped and she was switched over to aripiprazole and referred to a dermatologist for evaluation and work-up. Extensive laboratory investigations carried out did not yield any abnormality suggestive of the cause of the oedema or skin lesions. She, however, did not consent to biopsy. A diagnosis of acute allergic angioedema with urticaria was made.

The skin lesions cleared about the third day of olanzapine withdrawal though it took up to nearly a week after olanzapine withdrawal for the oedema to resolve completely (Figures $2 \& 3$ ). She remained mentally stable, tolerating the aripiprazole well. However, about five months later, aripiprazole was not available in the hospital and market within the region. She resorted to her previously left-over olanzapine pending the procurement of additional aripiprazole when available. Unfortunately, 2 days later, the lesion reappeared, now on the face mainly. She was re-introduced to aripiprazole and had remained generally stable for close to 12 months before this report was written.

There was no associated use of herbal drugs or any other medications including those known to be associated with such a reaction (like penicillin, nonsteroidal antiinflammatory drugs (NSAIDs), among others). She had also not had any allergic reaction in the past nor was she allergic to any food or drink.

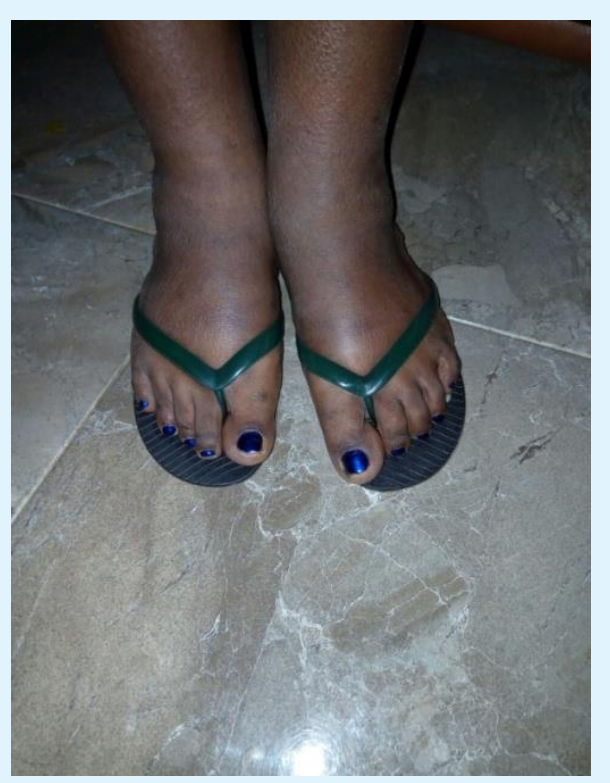

Figure 1A: Day 2 of olanzapine withdrawal. 


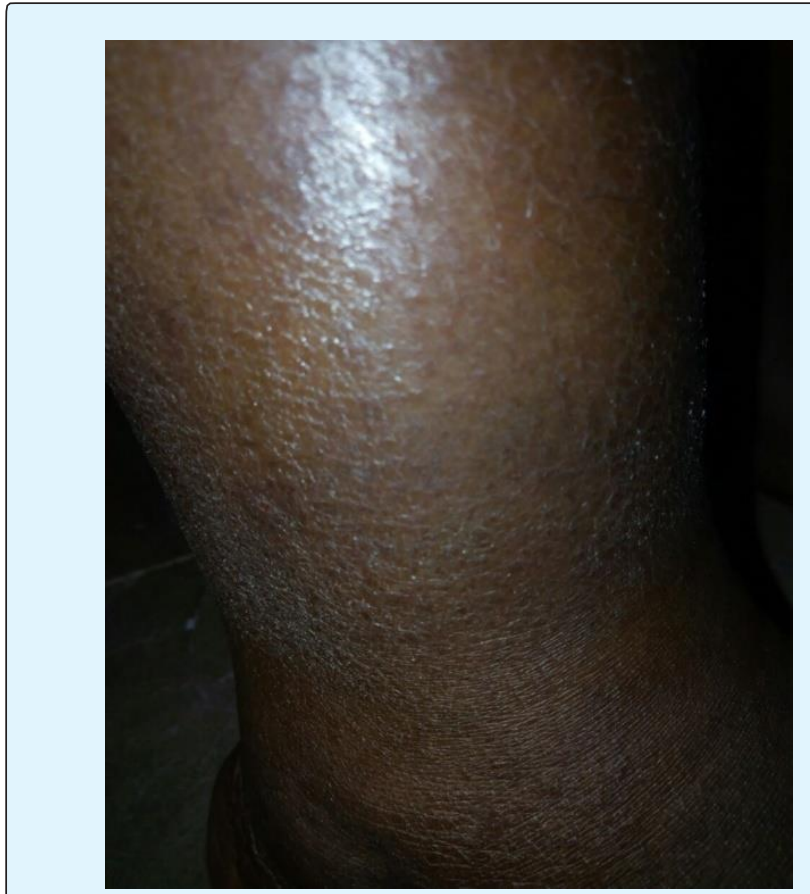

Figure 1B: Day 2 of olanzapine withdrawal [skin lesion \& oedema relieving].

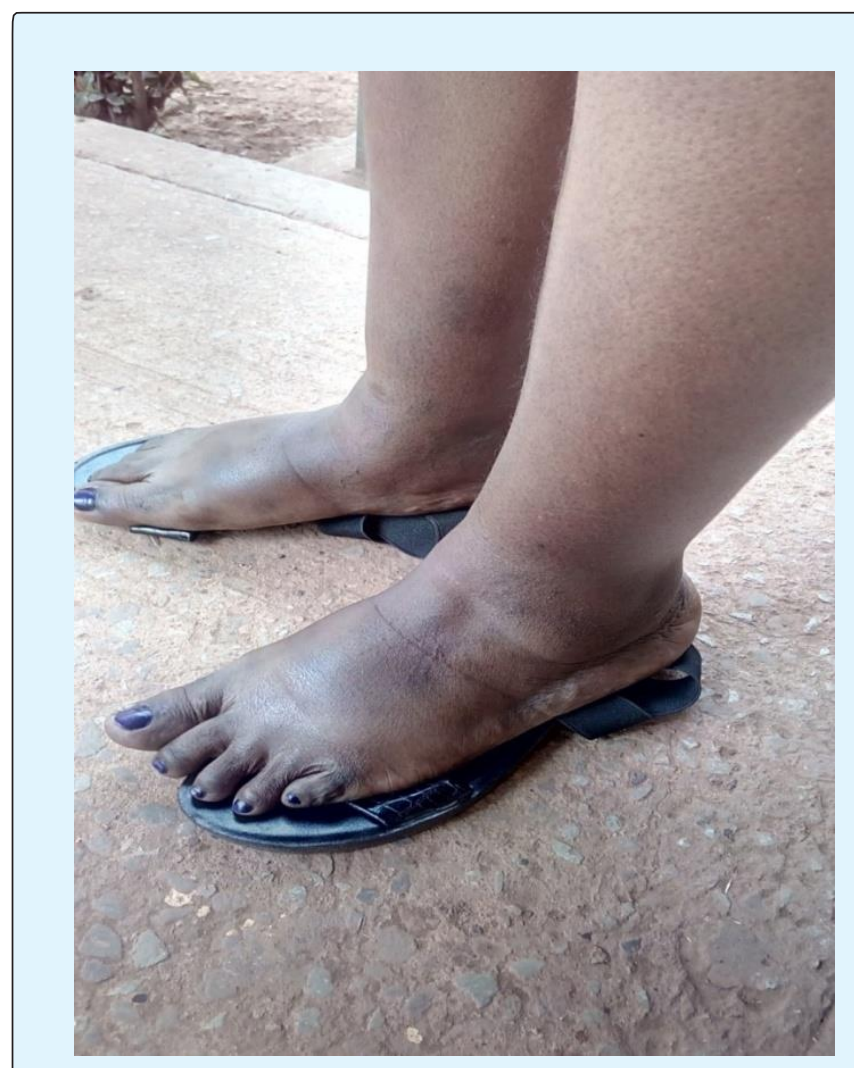

Figure 2: Day 3 of olanzapine withdrawal.

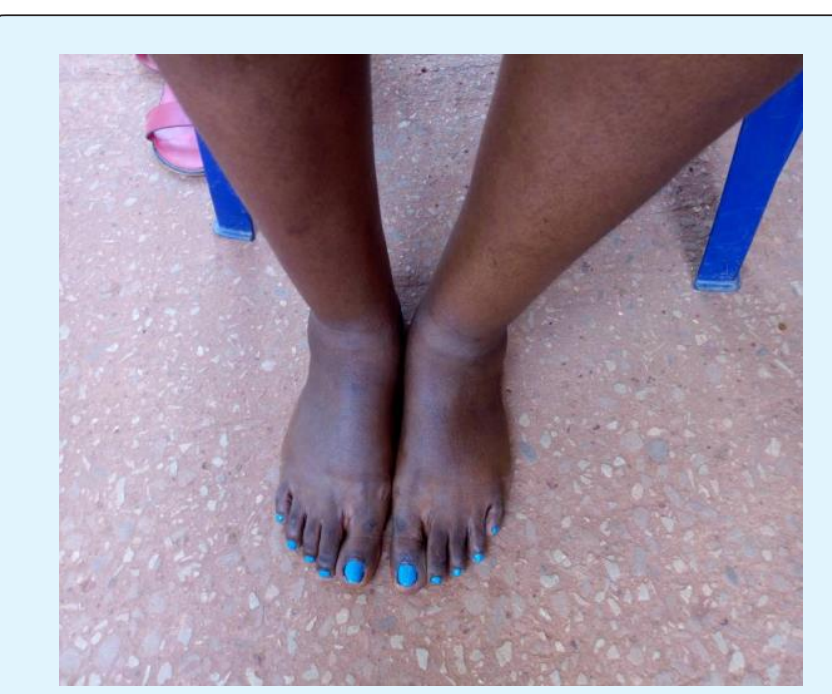

Figure 3: Day 7 of olanzapine withdrawal.

\section{Discussion}

Drug-related skin reactions are probably underreported and because some forms of them could be mild and self-limiting, physicians are often not prompted to verify drug-induced cutaneous reactions until the lesion is persistent or severe.

Olanzapine-induced skin eruptions have been described previously, such as: erythematous skin lesions which developed in dependent areas on the eight day of olanzapine treatment of an 82-year-old lady with agitated delirium secondary to pulmonary embolism [8]; acute generalized exanthematous pustulosis which occurred mainly on the neck and face after 5 days of introduction of olanzapine to a 56 year old Caucasian male with a longstanding history of mood disorder [10]; hundreds of (multiple) yellowish umbilicated papules on the arms, legs, and trunk of a 31-year-old white man with schizophrenia on long-term psychiatric medications who was switched to olanzapine some 8 weeks earlier [6], and fixed drug eruptions that appeared on the limbs and trunk of a 39-year-old man with alcohol dependence syndrome and first episode of mania 10 days after he was commenced on olanzapine [15].

Acute allergic angioedema is known to almost always occur with urticaria within few hours of exposure to an offending agent. That was the case in our patient.

Our patient had a re-occurrence of the lesion when, on her own, she had a rechallenge. Recurrence has been reported in few cases where there was a re-challenge with the offending olanzapine [8]. The case of the woman 


\section{Clinical Dermatology Open Access Journal}

reported by Duggal and colleagues had her rashes resolved when olanzapine was replaced with risperidone but when she was switched back to olanzapine because of unbearable dizziness she experienced with risperidone, the rashes reoccurred [8].

The caesation of the skin lesion shortly after the discontinuation of olanzapine supports earlier reports of antipsychotic-related adverse reaction resolving on withdrawal of the offending drug [16,17].

The mechanism by which olanzapine causes skin eruptions are not very clear but it is likely to be via the general mechanism of drug reactions postulated to be immune and non-immune aetiology [18], though in some cases, the drug hypersensitivity reactions are difficult to classify because of the lack of evidence supporting the predominant immune mechanism. Our patient may fall into the last group of unpredictable idiosyncratic nature.

It is not certain why our patient developed a skin reaction to olanzapine but she had some risk factors known to generally increase the chances of developing cutaneous drug reactions: being a female and her age (being an adult). Using the Naranjo Causality Scale [19], a scale for adverse drug reaction to establish a causal link of the skin lesion and olanzapine medication, we got a total score of '7' indicating "probable cause". Unfortunately, we could not perform the skin biopsy (for histology) as the patient objected. We are convinced that the skin lesion that our patient had was due to her medication olanzapine. The rapid onset upon reintroduction, and reversibility of the skin rashes following discontinuation of the drug, suggest a causal link.

\section{Conclusion}

Adverse cutaneous drug reactions are distressing to both the patient and the physician. It is better if we can prevent them from happening. Drug reactions are a common reason for litigation, especially these days in Nigeria that many are out to reward their physicians negatively. We need not ignore or take lightly the need to warn every patient about potential adverse effects and prescribers should also enquire to avoid prescribing a medicine to a previously sensitized patient.

Awareness of this rare side effect will allow psychiatrists educate their patients about the drug adverse effects and to be on the watch and report any similar reaction on time and when identified or suspected, appropriate management steps, including withdrawal of the offending drug and referrals could be promptly instituted.

\section{References}

1. Sadock BJ, Sadock VA (2007) Kaplan \& Sadock's synopsis of Psychiatry: behavioural sciences/clinical psychiatry. 10 $0^{\text {th }}(E d n$.$) , Lippincott Williams \& Wilkins,$ Philadelphia, USA, pp: 1094.

2. Lasić D, Cvitanović MZ, Uglešić B, Višić V, Hlevnjak I (2011) Exanthema medicamentosum as a side effect of promazine. Psychiatria Danubina 23 (2): 194-197.

3. Mishra B, Sahoo S, Sarkar S, Akhtar S (2007) Clozapine-induced angioneuroticoedema. Gen Hosp Psychiatry 29(1): 78-80.

4. Lai YW, Chou CY, Shen WW, Lu ML (2012) Pityriasisrosea-like eruption associated with clozapine: a case report. Gen Hosp Psychiatry 34(6): 703.e5-7.

5. Akay BN, Sanli H (2009) Symmetrical drug-related intertriginous and flexural exanthem due to oral risperidone. Pediatr Dermatol 26(2): 214-216.

6. Chang HY, Ridky TW, Kimball AB, Hughes E, Oro AE (2003) Eruptive xanthomas associated with olanzapine use. Arch Dermatol 239(8): 1045-1048.

7. Prevost P, Bédry R, Lacoste D, Ezzedine K, Haramburu F, Milpied B (2012) Hypersensitivity syndrome with olanzapine confirmed by patch tests. Eur J Dermatol 22(1): 126-127.

8. Duggal MK, Singh A, Arunabh, Lolis JD, Guzik HJ (2005) Olanzapine-induced vasculitis. Am J Geriatr Pharmacother 3(1): 21-24.

9. Papaioannides D, Sinapidis D, Korantzopoulos P, Charalabopoulos K (2006) A case of cutaneousvasculitis associated with olanzapine. Int J Low Extrem Wounds 5(2): 116-117.

10. Christen S, Gueissaz F, Anex R, Zullino DF (2006) Acute generalized exanthematous pustulosis induced by olanzapine. Acta Medica (Hradec Kralove) 49(1): 75-76.

11. Jhirwal OP, Parsad D, Basu D (2004) Skin hyperpigmentation induced by olanzapine, a novel antipsychotic agent. International Journal of Dermatology 43(10): 778-779.

12. Solfanelli A, Curto M, Dimitri-Valente G, Kotzalidis GD, Gasperoni C, et al. (2013) Skin Rash Occurring with Olanzapine Pamoate, but not with Oral Olanzapine, in 


\section{Clinical Dermatology Open Access Journal}

a Male with Juvenile Idiopathic Arthritis. J Child Adolesc Psychopharmacol 23(3): 232-234.

13. Singh LK, Sahu M, Praharaj SK (2015) Olanzapineinduced reversible pellagroid skin lesion. Curr Drug Saf 10(3): 251-253.

14. Sengupta S, Chetia DJ, Nath S, Timungp B (2015) Olanzapine induced Stevens-Johnson Syndrome. Delhi Psychiatry Journal 18(1): 206-207.

15. Chawla N, Kumar S, Balhara YPS (2017) Olanzapineinduced skin eruptions. Indian J Psychol Med 39(4): 537-538.

16. Umar MU, Abdullahi AT (2016) Self-limiting atypical antipsychotics-induced oedema: Clinical cases and systematic review. Indian J Psychol Med 38(3): 182188.

17. Obayi NOK, Igwe MN, Ndukuba AC, Achor JU, Adagam G, Ojiako IS, et al. (2016) Risperidone-related pedal oedema: Report of two cases from Nigeria. Nigerian Journal of Psychiatry 14(2): 48- 53.

18. Lamer V, Lipozenčić J, Turčić P (2010) Adverse cutaneous reactions to psychopharmaceuticals. Acta Dermatovenerol Croat 18(1): 56-67.

19. Naranjo CA, Busto U, Sellers EM, Sandor P, Ruiz I, et al. (1981) A method for estimating the probability of adverse drug reactions. Clin Pharmacol Ther 30: 239245. 